\section{Comment}

The pre-injury hearing level in case 1 is unknown, but the pattern of the hearing loss, its severity in a woman of this age, and her apparently previously normal hearing strongly suggest a causal link. In case 2 , the subject had a pre-existing hearing loss, but his hearing deteriorated substantially in the right ear-at $1 \mathrm{kHz}$ and in the higher frequencies. Alteration of hearing at $1 \mathrm{kHz}$ is unusual but recognised after noise trauma. Both subjects perceived an immediate threshold shift, which decreased in severity with time and so was not as great by the time audiometry was performed.

The inflation of an air bag is triggered by vehicle deceleration and can generate a sound pressure level of $150-170 \mathrm{~dB}$ in $<100 \mathrm{~ms}^{4}$ The level depends on the size of car, number of occupants, ventilation, size and number of air bags, and inflation rate. In a study of the effect of air bag "slap" on the ears of squirrel monkeys, the researchers found no permanent hearing damage, ear drum perforation, or disruption of ossicles in air bag velocities of up to $100 \mathrm{mph}$ with a sound pressure level on inflation of $150 \mathrm{~dB} .^{5}$ None the less, this level might cause acoustic trauma in some humans. Cochlear damage may arise from the effects of noise or blast injury. The likelihood of damage depends on the noise level, the exposure time, and individual sensitivity.

Injury from air bags may be more likely in the future. Current safety design is moving towards vehicles with air bags that inflate in frontal and side crashes for both front seat positions. Lack of space means that side air bags inflate very quickly and are closer to the ear.

It is surprising that hearing loss is not reported more frequently after air bag inflation. Any loss identified is perhaps ascribed to other factors associated with a car accident. Also, in an accident the victim is unlikely to register and remember the noise of the air bag. It is therefore unclear whether these cases are isolated or represent a more widespread occurrence.

Contributors: GB had the original idea, NS advised on and carried out the audiometric testing, and RF provided information on air bag construction and literature on testing. The paper was jointly written by all three authors. GB will act as guarantor.

Funding: None.

Competing interests: None declared.

1 Third report to Congress. Effectiveness of occupant protection systems and their use (http://www.nhtsa.dotgov:80/cars/rules/rulings/208con2e. html).

2 Antosia RE, Partridge RA, Virk AS. Air bag safety. Ann Emerg Med 1995;25:794-8.

3 Saunders JE. Slattery WH III, Luxford WM. Automobile airbag impulse noise: otologic symptoms in six patients. Otolaryngol Head Neck Surg 1998:118:228-34

4 Rouhana SW, Webb SR, Wooley RG, McCleary JD, Wood FD, Salva DB. Investigation into the noise associated with air bag deployment. Part 1. Measurement technique and parameter study. Warrendale, PA: Society of Automotive Engineers, 1994. (Report 942218.)

5 Richter HJ II, Stalnaker RL, Pugh JE Jr. Otologic hazards of airbag restraint system. Society for Automotive Engineers, 1974. (Paper No 741185; can be ordered through the SAE at www.sae.org.)

(Accepted 23 October 1998)

\title{
Questionnaire survey of advice given to patients with fractures
}

\author{
Badal Pal
}

Editorial by Doube

South Manchester

University Hospitals

NHS Trust,

Withington

Hospital, West

Didsbury

Manchester

M20 2LR

Badal Pal,

consultant

rheumatologist

bpal@fs1.with.man. ac.uk

BMJ 1999;318:500-
Osteoporosis, which contributes to some 150000 fractures annually, cost the NHS $£ 750$ million in $1994,{ }^{1}$ and current estimates exceed this figure. Department of Health guidelines on osteoporosis published in November $1994^{1}$ recommend an aggressive approach, even in patients with established osteoporosis. Guidelines from the Royal College of Physicians also exist with regard to aspects of rehabilitation in fracture management. ${ }^{2}$ What advice (relating especially to rehabilitation as well as assessment and treatment of osteoporosis) patients with fractured hip and vertebrae actually receive is not known.

\section{Patients, methods, and results}

Names and addresses of 96 patients with recent fractures were obtained (in the latter part of 1996) from 56 hospital based orthopaedic surgeons in the Greater Manchester area (out of 70 contacted) who each selected up to two patients at random; 14 further names were obtained through announcements in the local evening newspaper. A detailed questionnaire seeking information on advice and treatment was mailed to these 110 patients; 82 completed questionnaires were returned (response 74.5\%). Most patients were retired. Past occupations were mainly sedentary, and 19 of the women were housewives.

Awareness of osteoporosis as brittle bone disease and its risks was reported by 34 patients. Sources of this knowledge were doctors in only 10 and the media or friends or relatives in the rest. Most patients (61) were discharged home directly from the orthopaedic ward, but a smaller number (8) required a further period of rehabilitation in the geriatric or rehabilitation ward before discharge (13 patients did not answer this question). Other important findings are given in the table.

\section{Comment}

Patients with fracture have limited knowledge and awareness of osteoporosis, and the information that they do have seems to come mainly from the media rather than from professionals. Orthopaedic surgeons apparently do not place much importance on lifestyle factors such as smoking or excess alcohol consumption in their dealings with patients with fracture. A greater emphasis needs to be placed on public health education in general and specifically in patients who have already suffered a fracture. 
Clinical data and treatment and advice received by patients with fracture. Values are numbers of patients unless stated otherwise

\begin{tabular}{lc} 
Detail & $\begin{array}{c}\text { Fracture patients } \\
(\mathbf{n}=\mathbf{8 2})\end{array}$ \\
\hline No of women & 71 \\
\hline Mean (range) age (years) & $69.6(36-94)$ \\
\hline History of prednisolone therapy & 5 \\
\hline Physiotherapy: assessment and advice & 53 \\
\hline Occupational therapy: assessment and advice & 21 \\
\hline Advice regarding diet and calcium supplements & 27 \\
\hline Bisphosphonates & 12 \\
\hline External hip protector & 0 \\
\hline Advice given regarding smoking* & 4 \\
\hline Advice given regarding alcohol consumption & 10 \\
\hline In women only: & 13 \\
\hline Hysterectomy & 7 \\
\hline Hysterectomy plus oophorectomy & 13 \\
\hline Hormone replacement therapy: & 6 \\
\hline Currently & 52 \\
\hline Previously & 8 \\
\hline$\quad$ Never & \\
\hline Advice regarding hormone replacement therapy & \\
\hline *19 Smokers. &
\end{tabular}

Inadequate or incomplete advice had been given, specifically with regard to assessment and advice about physiotherapy and occupational therapy, and only a few received any specific treatment with regard to reduction in risk of future fracture, such as hormone replacement therapy, bisphosphonates, or even calcium and vitamin D supplements, all of which are now of proved value in elderly patients. ${ }^{3-5}$ Guidelines from the Department of Health and the Royal College of Physicians are, therefore, not followed in this group of patients and this may reflect similar practice elsewhere in the country.

The role of external hip protectors is underestimated by orthopaedic surgeons as, in this group, they had not been prescribed at all. These devices are now available "off the shelf" and in different sizes. Newer evidence has emerged regarding the value of this simple aid towards prevention of fracture. ${ }^{5}$ In an elderly population drug intervention for osteoporosis may be inconvenient and of no early benefit, whereas the use of external hip protectors can have an immediate effect. As such devices have become easier to use and more patient friendly (and they are relatively cheap at around $£ 30$ each) orthopaedic surgeons, physicians, and general practitioners should all be aware of the benefits and consider their provision, especially in very elderly patients with a tendency to fall.

Findings from this survey indicate that there is room for improvement in services to patients with established osteoporosis, such as those with recent fractures, as there is now increasing evidence that interventions can be helpful and reduce the impact of fractures and associated cost and morbidity in the community.

Written policies should be established in orthopaedic units for automatic referral of patients with low trauma fracture to an interested specialist in the area, and general practitioners should consider taking on such referral and management.

I thank all the orthopaedic surgeons and the patients who helped in this survey, and Miss Alison Webb for typing the manuscript. Mr B N Muddu, orthopaedic surgeon, Tameside General Hospital, Ashton under Lyne, helped in contacting orthopaedic surgeons in the area. Mrs J Morris processed the questionnaires and performed statistical analysis.

Contributors: $\mathrm{BP}$ is the only contributor.

Funding: This research was part of a project made possible by a fellowship from the Overseas Doctors' Association and assistance from Proctor and Gamble Pharmaceuticals.

Competing interests: None declared.

1 Barlow DH. Advisory group on osteoporosis report. London: Department of Health, 1994.

2 Royal College of Physicians. Fractured neck of femur: prevention and management. Summary and recommendations of the report. $J R$ Coll Phys Lond 1995;23:8-12.

3 Scheiber II LB, Torregrosa L. Evaluation and treatment of postmenopausal osteoporosis. Semin Arthritis Rheum 1998;27:245-61.

4 Van Staa TP, Abenhaim L, Cooper C. Use of cyclical etidronate and prevention of non-vertebral fractures. Br J Rheumatol 1998;37:87-94.

5 Ekman A, Mallmin H, Michaelsson K, Ljunghall S. External hip protectors to prevent osteoporotic hip fractures. Lancet 1997;350:563-4.

(Accepted 29 September 1998)

\section{One hundred years ago \\ Cataract extraction in a lioness}

Professor Gustavo Pisenti, of the University of Perugia, has lately had a thrilling experience in extracting a cataract from a powerful lioness about three years old. The animal was placed in a suitable cage in the middle of the menagerie, and the first difficulty was the administration of an anaesthetic. The intervals between the bars of the cage were filled up with cotton wool, and a large packet of gauze impregnated with chloroform was placed in the cage, the door of which was then closed with a shutter. In about a quarter of an hour a reconnaissance was cautiously made, and the illustrious patient was seen lying stretched out, apparently in a condition of deep coma. She was then dragged out of the cage, bound and gagged. She was next placed on a table but before the operation could be begun she suddenly awoke, and struggled violently, rolling on to the floor, where the medical men "with admirable coolness, but not without intense emotion which might easily be seen in their countenances," held her down while the animal's head was wrapped in a towel steeped in sulphuric ether. The lioness, however, managed to free herself from the gag and partly from her bonds, and gave a roar which made the majority of the spectators beat a hasty retreat. But the ether overcame her, and Professor Pisenti with great pluck dragged her into the cage again, where the anaesthetic coup de grace was given by means of another packet of gauze steeped in chloroform. The beast's head was pulled out through the door of the cage and securely held in position. Professor Pisenti then operated with brilliant success. We have no doubt that the Professor had a more "serious time" than Artemus Ward had in getting into the uniform of the days of his youth, and we congratulate him heartily on having escaped a counter-operation by his formidable patient. A curious feature of the scene was the excitement produced among the other animals-zebras, bisons, leopards, wolves, hyenas, monkeys etc.-in the menagerie, who all inhaled some portion of the anaesthetics with which the air was saturated. (BMJ 1899;i:1489) 